\title{
CUNQUEIRO O EL SUEÑO COMO NECESIDAD VITAL
}

\author{
por \\ CONCEPCION SANFIZ FERNANDEZ
}

Según definición de Dujardin, toda la realidad consiste en la conciencia, clara o confusa, que uno tiene de ella ${ }^{1}$. En el caso de Cunqueiro, su visión de la realidad exterior es inseparable de su subjetividad artística. A su vez, el principal rasgo de ésta es la constante ensoñación. De ahí que la estructuración de las narraciones del escritor no sea concebible ni comprensible sin contemplar al sueño como pieza básica de la misma. El relieve que este elemento adquiere lo convierte en clave para la verdadera vida de los personajes:

Era la viva necesidad de la libertad, (...) de soñar los sueños de Fanto ${ }^{2}$, dice el narrador sobre este joven protagonista. El personaje, como su creador, sólo se realiza genuinamente cuando puede soñar, sin trabas ni prosaicas limitaciones del entorno. Cristina de la Torre resalta que los protagonistas se caracterizan por la cualidad irreductible de su espíritu, su capacidad de

' Recogido en: BOOTH, W. C.: La retórica de la ficción Ed. Bosch, Barcelona, 1974; pp. 373-74.

${ }^{2}$ Cunqueiro, A.: Vida y fugas de Fanto Fantini della Gherardesca, Desino, Barcelona, 1972, pp. 34.

"CUADERNOS DE ESTUDIOS GALLEGOS", Tomo XL, Fascículo 105, Santiago 1992. 
asombro e imaginación ${ }^{3}$. Capacidad de asombro e imaginación son rasgos estrechamente vinculados a la ocupación de soñar despierto, a la que el autor se dedica con tanta intensidad. Y esta ocupación, a pesar de lo que puedan creer los adictos al pragmatismo, no es en absoluto gratuita. Porque es la capacidad de imaginación (del hombre) la que impulsa el salto por encima del dolor y las limitaciones de la existencia. Para Cunqueiro (...) los sueños y las aspiraciones son la verdadera est fa del vivir ${ }^{4}$. Gracias a ellos, en sus novelas todo es posible, en particular lo extraordinario, pues todo depende de la manera de mirar la realidad ${ }^{5}$. Por tanto, la nueva realidad instaurada deriva de la ya existente. Lo único necesario es aplicarle una perspectiva nueva. Para Cristina de la Torre, las cuatro novelas publicadas originalmente en castellano (sobre las que centraremos el estudio) pertenecerían a dos grupos diversos, según el rasgo predominante en cada una de ellas. Así, mientras que Las mocedades de Ulises y Vida y fugas de Fanto Fantini se incluirían un el bloque denominado Sueño y realidad, Un hombre que se parecía a Orestes y El año del cometa, figurarían bajo el epígrafe Destino e identidad ${ }^{6}$. Sin rechazar esta clasificación, opinamos que en todas las novelas el papel del sueño es destacado. Itentaremos analizarlo a través de los propios textos que nos ocupan. Con este procedimiento, procuraremos además desentrañar la múltiple funcionalidad ejercida por el sueño en esta narrativa. Siguiendo un orden cronológico, comenzaremos por Las mocedades de Ulises. Una cita que alude tácitamente a los sueños, ilustra su enorme poder. Tal poder queda demostrado por su capacidad de lograr que el soñador pueda creer en algo gracias a haber conseguido crearlo: "Ulises tenía el don de sonreirse de sus imaginaciones; (...) sonreía (...) porque hallaba, de pronto, que el mundo era inmensamente rico y vario, y que eran innumerables los reinos desconocidos a los que una mirada asombrada y una voz fresca podía acercarse a levantar la punta del velo de encendido color que los cubría ${ }^{7}$.

En Las mocedades... incluso ese poder se convierte, si bien ocasionalmente, en maligno: esto ocurre cuando Jasón es obligado por su primer amo

\footnotetext{
${ }^{3}$ De la Torre, C. La narrativa de Alvaro Cunqueiro, Madrid, Pliegos, 1988, pp. 50.

${ }^{4}$ DE LA TORRE, C., Ob. cit., p. 21.

${ }^{5}$ DE LA TORRE, C., Op. cit., p. 22.

${ }^{6}$ DE LA TORRE, C., Ob. cit., p. 129.

${ }^{7}$ CUNQUEIRO, Alvaro, Las mocedades de Ulises, Barcelona, Destino, 1970, p. 250.
}

"CUADERNOS DE ESTUDIOS GALLEGOS", Tomo XL, Fascículo 105, Santiago 1992. 
a re-crear la historia de su vida. Bajo la presión del tirano, Jasón llega a decir no lo que él desea, sino lo que el otro le obliga a inventar, y -lo que es más grave-, a creer.

Me hacía volver al comienzo, cómo era mi casa, de qué hacíamos las púas de las cardas, cómo se llamaba mi abuelo, (...) iOh, horas y horas!.

Yo me caía de sueño. Decía lo que él quería.

- Claro, le mataste y huíste, (...) Siembre queda sangre en las uñas -me decía.

- Yo miraba mis uñas y veía la sangre. Sudaba,(...) Yo no maté a Liedea, pero veía su sangre en mis uñas. ${ }^{8}$

Sin embargo, los sueños recuperan sus connotaciones positivas al ser presentados como patrimonio privilegiado de los fabuladores, quienes alcanzan el máximo placer sintiéndose escuchados por un auditorio atento:

Cuando comienzo a decir la historia de Menelao voy subiendo, grado a grado, despacio, una ancha escalera, como la que hay en el ágora de los ítacos, (...)

- Me quito la roja capa de los días de fiesta (...) y la tiendo al aire, solamente un instante, para que el público pueda ver la sangre relampagueando en las batallas. ${ }^{9}$

(En textos como éste se hace además patente la vocación teatral de Cunqueiro, quien incluso en su narrativa cuidaba al máximo los gestos y movimientos de los personajes.)

Este enfoque del sueño, aparece en innumerables ocasiones a lo largo de la presente narración, principalmente cuando se centra la atención en Ulises. Pero también se refleja esta perspectiva en la actuación y en las palabras de varios de los personajes secundarios. Y es que en el libro hay más de un

\footnotetext{
${ }^{8}$ CUNQUEIRO, A. Ob. cit., p. 58.
}

Otra curiosa y atípica connotación negativa de los sueños, la hallamos en la paranoia del tirano de Zante. Temiendo que los aristócratas lo depusieran, ajusticiaba a todos aquellos cuyos sueños mostrasen una simbología sospechosa: Ganaba la vida denunciando al tirano los sueños de los aristócratas. El tirano tenía sofistas que averiguaban lo que escondían los sueños. Los ricos, con el miedo, soñaban en voz alta. Soñar con fuego era tener intención de quemar el palacio y soñar que uno era dueño de un águila, significaba apetito de sustituir al gran señor en la tiranía (ob. cit.; p. 85).

${ }^{9}$ CUNQUEIRO, Alvaro, Ob. cit., p. 128.

"CUADERNOS DE ESTUDIOS GALLEGOS", Tomo XL, Fascículo 105, Santiago 1992. 
contador de historias. ${ }^{10}$

Un sub-tipo de la ensoñación lo hallamos en las secuencias donde el sueño actúa como revulsivo del miedo y generador de confianza y optimismo. Ulises confiaba a Pretextos:

(...) Cuando comenzaba a temer la noche en los caminos, entre dos espesos paños de niebla, veía, abajo, el último rayo de sol en la arena y en el blanco muro amante de mi ciudad, y entonces se me ocurría cantar, y corría hasta entrar en el corral de mi casa cantando, y soñaba yo que mientras cantase, la niebla no me envolvería del todo y vería el camino con mi voz. ${ }^{11}$

El sueño, pues, sería luz vivificadora, en clara oposición a la amenaza de la oscuridad y el temor.

Hemos repasado así todas las connotaciones que el sueño tien en esta novela cunqueiriana. Tan sólo falta añadir que su principal protagonista resulta ser un soñador perseverante, pues incluso cuando su espera de Penélope le va minando las fuerzas y las ilusiones, es todavía capaz de soñar. Hasta diríamos que es algo casi fisiológico para él, y no puede evitar el hacerlo ${ }^{12}$. Esta observación cobrará nueva luz cuando confrontemos esta reacción con la de otros protagonistas de obras posteriores en el tiempo.

En Un hombre que se parecía a Orestes encontramos nuevas connotaciones que añadir a las ya observadas. Especial significación tiene la presentación del sueño como fuente de eterna juventud. En la figura de Ifigenia se ejemplifica la virtud de los sueños como ser antídotos contra el paso del tiempo. Este personaje vive con y para su sueño, reconociendo señales suyas en todo lo que le sucede, y es gracias a ello que se conserva como una muchacha, porque ella sabe que ésta su condición juvenil es necesaria

\footnotetext{
${ }^{10}$ En alguno de los personajes secundarios, la faceta de fabulador llega a alcanzar una importancia tal que se destaca incluso al reseñarlo en el índice onomástico que Cunqueiro incluye al final. Así, leemos acerca de Foción: El mundo habitado, la ecumene toda, iba y venía con él, con sus relatos, las lenguas extrañas y las canciones, y el infantil amor por las lejanas descubiertas. (CUNQUEIRO, A., ob. cit., pp. 289).

"CUNQUEIRO, Ob. cit., p. 243.

${ }^{12}$ No quiero decir cuánto esperó Ulises, los años ó los siglos, acaso. (...) Pero quiero decir simplemente que esperó, y ya se sentía más que maduro, y se le antojaba podredumbre la madurez, de tan cansado, sólo, y no más que un vago sueño por amigo cotidiano... (Cunqueiro, Ob. cit., p. 259).
}

"CUADERNOS DE ESTUDIOS GALLEGOS", Tomo XL, Fascículo 105, Santiago 1992. 
para el cumplimiento de su sueño ${ }^{13}$.

Curiosamente, aquí figura otra connotación del sueño no tan atractiva, pues éste parece ejercer una cierta tiranía sobre quien lo vive, exigiéndole unas determinadas condiciones para poder realizarse.

Otra cara de la moneda viene representada por la llegada de la muerte en el instante en que se deja de soñar ${ }^{14}$ :

Y mi padre, desde aquel día, no soñaba más que con alancear dragones, y que venía desde Aviñón un pintor de milagros a retratarle al lado de la bestia muerta (...) Y murió mi padre de no poder ver cumplido su sueño ${ }^{15}$.

Este cese de la actividad imaginativa supone, pues, una frustración. Pero también el sueño puede indicar esto mismo. El efecto que este desdoblamiento de facultades produce se asemeja al de una fusión de contrarios. Y una muestra de tal caso lo hallamos en el propio Orestes, que cada vez que imaginaba un viaje, inevitablemente lo hacía desembocar en una historia de amor, y reflexionando en ello lo atribuía a su soledad vagabunda, más que al deseo sexual ${ }^{16}$. Por tanto, el personaje proyecta en su sueño su principal carencia: la de calor humano. En otro pasaje en que aparecen nuevamente vinculados sueños y amor, se interpreta el intercambio de éstos entre los amantes como prueba de entrega total. Esta perspectiva es coherente con la relevancia vital que Cunqueiro le otorga al soñar:

Los corazones son vasos llenos de caliente jengibre. ¿Quién osará añadir la gota que los hará verter?.(...) Mejor sería llenarlos con nuestros sueños, y beber un poco yo de lo tuyo y tú de lo mío. ${ }^{17}$

Aunque en toda la narrativa del autor gallego la memoria tiene un peso específico, hay casos en que se identifica hasta tal punto con lo soñado, que ambos se funden en un único elemento:

Cuando pisó tierra argólida al cabo de tantos años de ausencia, reconoció en el aire un frescor perfumado que más de una vez, durmiendo en su tienda de piel, lo había despertado, como si por un roto entrase una

\footnotetext{
${ }^{13}$ CUNQUEIRO, A., Un hombre que se parecía a Orestas, Destino, Barcelona, 1969, p. 37

${ }^{14}$ Esta faceta aparece desarrollada de forma extensa en El año del cometa, como veremos luego.

${ }^{15}$ CUNQUEIRO, Ob. cit., p. 62.

${ }^{16}$ CUNQUEIRO, Ob. cit., p. 142.

${ }^{17}$ CUNQUEIRO, Ob. cit., p. 193.
}

"CUADERNOS DE ESTUDIOS GALLEGOS", Tomo XL, Fascículo 105, Santiago 1992. 
corriente de aire a golpearle la frente. Ahora recordaba que esto sucedía cuando soñaba con los veranos de su país natal, del que no tenía más noticias que aquel soplo aromático. ${ }^{18}$

Sin embargo, y a pesar de todas estas interpretaciones de nuestro concepto básico, en esta segunda novela la faceta del sueño que se pone más de relieve es una que ya aparecía en el Ulises cunquiriano. Se trata del poder creador, que el texto parece querer ratificar una y otra vez: así, Egisto llega incluso a temer que la realidad se le antoje copiar a su efervescente imaginación:

Me distraía Egisto inventando coincidencias, y al final siempre se asustaba, temiendo que la realidad se diese a imitar sus imaginaciones. ${ }^{19}$

El escritor plasma sus sueños en el texto, y así llega un momento en que éste adquiere vida propia:

Todo lo que está escrito en un libro, lo está al mismo tiempo, vive al mismo tiempo. ${ }^{20}$

Esta es, quizás, la expresión que mejor sintetiza el sentido fundamental que el concepto adquiere para nuestro autor.

El cultivo de los sueños está directamente relacionado con el fomento de los ideales. La vinculación entre ambos se indica en Vida y fugas de Fanto Fantini, desde las primeras páginas:

Fanto se imaginaba batallas en campo abierto, en las que hallarían muerte y enrojecerían el pico del cuervo los cadáveres del sobrino del Imperante, el lozano duque de Provenza, y el nuevo Lanzarote del Lago. Golpeaba en su puerta el signor Capovilla diciendo que ya era hora de salir para Florencia, y en el patio del mesón "Artemisa" contemplaba con sorpresa y melancolía el caballo del cavaliere, un castrado ruano colitrensado, que osaba mirarle a los ojos y relinchar. Cada quisque sueña lo que puede. ${ }^{21}$

Esta misma cita nos sirve para comentar una connotación negativa del acto de soñar (como vamos viendo, tales connotaciones son minoría, pero en cada novela aparece alguna. Tal vez constituyan la advertencia de que no todo es ideal, de que incluso en el mundo de Cunqueiro existen los claros-

\footnotetext{
${ }^{18}$ CUNQUEIRO, Ob. cit., p. 209.

${ }^{19}$ CUNQUEIRO, Ob. cit., p. 124.

${ }^{20}$ CUNQUEIRO, Ob. cit., p. 98.

${ }^{21}$ CUNQUEIRO, Vida y fugas de Fanto Fantini della Gherardesa, pp. 35-6
} 
curos). Los personajes cuya muerte anhela Fanto son otras tantas invenciones de su imaginación. Equivalen a papeles que se ve obligado a representar, de los cuales se halla hastiado. Y es así como, paradójicamente, su máximo sueño es acabar con esas personalidades que él mismo había soñado, para quedarse sólo con su auténtico yo.

Sin embargo, en esta novela comienzan a ganar terreno las sombras sobre las luces. El soñador no puede evitar la oscuridad que se cierne sobre él, y contra la que sus imaginaciones se estrellan en medio de la melancolía. Esta situación es la de Fanto cuando toma conciencia, en sus últimos tiempos, de la vejez y la enfermedad.

Si en Vida y fugas de Fanto Fantini, el final de la acción parecía teñir de tristeza la figura del soñador, en El año del cometa, las sombras ya amenazan a Paulon desde un momento temprano:

(...) Por la mente de Paulos pasó, dolorosa, la consideración de si sus sueños serían, respecto a la milagrización de la ciudad y del mundo, lo que el feble y falso relincho del bayo Aquiles, inaudible incluso en la callada noche. ${ }^{22}$

El asombroso poder creador del sueño ya no es contemplado como una cualidad incuestionable. La cradibilidad se resquebraja. El principal factor responsable es el cruel paso del tiempo, que parece querer erigirse en vencedor sobre las ensoñaciones y aspiraciones del hombre, y que ya se había cernido amenazador sobre Fanto o sobre Orestes.

A pesar de todo, el amor de la mujer constituye un estímulo importantísimo para que el soñador continúe haciendo vivir su imaginación. Es a su enamorada a quien dedica toda su actividad, pues ella es también su mejor auditorio. Pero Paulos tiene que luchar incesantemente contra la incertidumbre, y llega a avergonzarse de aquello que había sido su orgullo:

$Y$ viendo acercarse por un sendero a la derecha (...) a dos que serían pastores, a juzgar por los cayados y los zurrones, tuvo como verguenza, $y$ por primera vez en su vida, de las farsas de sus sueños, y estuvo a punto de cubrirse con la capa negra que llevaba doblada. ${ }^{23}$

El deterioro avanza de modo alarmante. El protagonista pierde de forma progresiva su facultad soñadora:

${ }^{22}$ CUNQUEIRO, El año del cometa con la batalla de los cuatro reyes, Barcelona, Destino, 1974, p. 84.

${ }^{23}$ CUNQUEIRO, Ob. cit., p. 167.

"CUADERNOS DE ESTUDIOS GALLEGOS", Tomo XL, Fascículo 105, Santiago 1992. 
Paulos no había sido capaz de soñarle al rey de Jerusalén motivos que le obligasen a comparecer a la hora de la batalla. ${ }^{24}$

Y sólo la recupera momentáneamente en algún episodio. ${ }^{25}$

Pero estos intentos de superación del mal que se cierne sobre él, parecen ser, por desgracia, las últimas tentativas fallidas de una actitud vital que ofrece una debilitada resistencia a la realidad material. Por otra parte, las circunstancias difíciles en que ésta le sumerge son otros tantos colaboradores a la desintegración. Y, cuando Paulos es presa de la fatiga y del hambre, ya no se siente en condiciones de hilvanar historias.

Efectivamente, con el término de la novela llegan también el fin y la destrucción del soñador. Los síntomas que preceden al instante crucial son: pérdida de la sensibilidad, decisión de abandonar el cultivo de los anhelos y aspiraciones, apatía, intención de borrar todo lo almacenado en la memoria y preocupación por lo material (llegando hasta la avaricia). Reunidos todos estos factores, se desencadena el desastre:

Otra de las razones (de la muerte de Paulos), y quizá la principal y primera, fué que había dejado de soñar. Que ya no soñaba, y entonces ya no era Paulos capaz de volar en el espacio en busca de tiempos y rostros idos o futuros, Paulos el soñador, sino un joven rico y ocioso, como cualquier otro, en una ciudad provinciana ${ }^{26}$.

El personaje olvida su costumbre de elevarse por encima de la realidad externa, a inmediatamente su mundo se empobrece y su idealismo es sustituído por un materialismo desconsolador. Si confrontamos la conclusión de esta novela con la de las anteriores, confirmamos el incremento progresivo de la melancolía. ¿Es el paso del tiempo, al igual que en su novela, el responsable de que le suceda esto a Cunqueiro?. Ciertas declaraciones del propio autor parecen afirmarlo así ${ }^{27}$. Quizás la interpretación de Martínez Torrón

${ }^{24}$ Ibidem, p. 178.

${ }^{25}$ Por ejemplo, en el episodio vivido con doña Ginebra en la corte del Rey Arturo: Lo gracioso del asunto es que, despertando Paulos, tenía sobre el corazón ese dulce peso que queda de los sueños de amor, como si de verdad hubiese jugueteado con dama Ginegra, haciendo manitas (CUNQUEIRO, Ob. cit., p. 200).

${ }^{26}$ CUNQUEIRO, Ob. cit., p. 231.

${ }^{27}$ El mismo (Cunqueiro) se define como un hombre a quien le gusta la vida que ve con cierta melancolía cómo se van los años.

MILIAN, MARITZA, E.: La actualidad en la obra de Alvaro Cunqueiro UNIV of Virginia, Virginia, 1981; pp. 40.

"CUADERNOS DE ESTUDIOS GALLEGOS", Tomo XL, Fascículo 105, Santiago 1992. 
contribuya también a clarificar el problema: Si sus protagonistas (los de Cunqueiro) reflejan a veces el cansancio de la vida, la fatiga de vivir, ello se debe a la imposibilidad de la Edad de Oro, pues las horas más felices son las del sueño, aunque luego se evidencia que esta Edad de Oro del sueño es imposible, y se desiste de la vida. La broma es entonces "una manera activa de consolarse" 28 .

Volveremos sobre esta faceta del sueño cuando lleguemos a las conclusiones de nuestro análisis. Pero antes debemos comentar brevemente otras connotaciones del concepto que están presentes en El año del cometa.

Especialmente significativa es la presentación de Fagildo, personaje secundario que encierra una de las interpretaciones del término sueño más hermosa y delicada de toda la novelística de nuestro escritor:

El ermitaño se preguntaba cómo hacer comprender a la niña su bondad y su inocencia, la inocencia de Fagildo, un pacífico rezador, que ayudaba a soñar a las gentes. A las gentes que se llevaban con ellas las palabras de Fagildo, y las usaban como si fuesen vida, las metían en su vivir cotidiano, las creían y hacían con ellas las mujeres en sus vientres un niño y una niña. ${ }^{29}$

Igualmente significativo es su comentario acerca de la forma de concebir sus historias: Siempre me ha apetecido construir mis narraciones como viajes, o como una confluencia de viajeros en un lugar dado (...) para llegar a la conclusión de la inutilidad de tal viaje: Orestes no llega (...) Paulos muere cunado regresa y deja de soñar... para llegar al final de la soledad y de la destrucción, el héroe ha vivido la plenitud humana y soñadora, tocado las cosas visibles e invisibles, habitado el misterio con vivacidad, ejercido poderes mágicos como en sueños.

A pesar del pesimismo que encierran estas declaraciones se advierte un rayo de esperanza en el reconocimiento de la profundidad y riqueza con que los personajes han vivido hasta el instante de su aniquilación. La misma impresión se desprende de la frase con que se cierra el párrafo:

Una frase de Henri Michaux (...): No hay necesidad de opio; todo es droga para quien elige vivir del otro lado, me parece convenir muy bien a cierta intención de mis narraciones.

(Ambas citas se recogen en: MARTINEZ TORRON, D.: La fantasía lúdica de Alvaro Cunqueiro. Eds. do Castro, Sada, 1980; pp. 5-6, que pertenecen al prólogo de Alvaro Cunqueiro)

Escuchando al escritor, parece, pues, que todavía queda una puerta abierta para la imaginación y el entusiasmo.

${ }^{28}$ MARTINEZ TORRON, D.: La fantasía lúdica de Alvaro Cunqueiro, ob. cit., pp. 51.

${ }^{29}$ CUNQUEIRO, A.: El año del cometa..., ob. cit., pp. 49.

"CUADERNOS DE ESTUDIOS GALLEGOS", Tomo XL, Fascículo 105, Santiago 1992. 
He aquí una clara alusión al poder creador de la palabra, la cual es, a su vez, componente básico de los sueños cunqueirianos. Sobre esta capacidad de realizar conjuros verbales (llamémoslos así) que generan la nueva realidad, dice A. Tarrío:

$O$ soño é esencial na obra do Mindoniense, pero non a experiencia onírica común, senón a ensoñación que resulta de ve-la realidade pasada pola lingua. E a propia lingua quen produco o prodixio da realidade. ${ }^{30}$

¿Qué tiene de innovador el enfoque de Fagildo, frente al de otros soñadores?.Fundamentalmente su altruismo. Otros personajes necesitaban del sueño para sus vidas. Sin embargo, el ermitaño sueña para los demás, para aquellos a quienes puede ayudar de este modo a ser felices. Esta generosidad del personaje es la misma que Carlos Rojas percibe en el mismo Cunqueiro:

Alvaro Cunqueiro nos ayuda a vivir. Por un momento indeciso y deslumbrante (...) el novelista nos transforma a imagen y semejanza del ser portentoso que todos somos sin advertirlo (...) Comparte con nosotros la existencia indecible y fantasiosa que lo desborda y así nos lleva a redescubrirnos, o dicho de modo quizás más preciso, a renacer. ${ }^{31}$

Otra perspectiva nueva que se abre sobre nuestro tema viene dada por la concepción del sueño como vía de conocimiento trascendente:

-En una novela, un joven se preguntaba qué sería de él si una mujer hermosa un día le apretaba la mano de una cierta manera.

- ¿La conocía o la soñaba?

${ }^{30}$ TARRIO, A.: Alvaro Cunqueiro ou os disfraces da melancolía. Galaxia, Vigo, 1989; pp. 36

(La referencia, en la secuencia comentada, al poder de la palabra, ha sido también percibida con acierto por Cristina de la Torre, en su obra ya citada, pp. 73).

${ }^{31}$ ROJAS, C.: Alvaro Cunqueiro y la resurrección de los mitos, Jano, 7 de Noviembre, 1973; pp. 117.

La otra cara de la moneda bien pudieran representarla secuencias como ésta: Por vez primera, también, se daba cuenta de que el juego de los sueños, con los sueños, lo apartaban de la comunidad humana. En realidad, nada le alegraba ni le dolía. Se preguntaba si amaba a alguien.

(CUNQUEIRO, A. El año del cometa..., ob. cit., pp. 168).

Se establece aquí una contraposición entre el soñar de Fagildo, fructífero y enriquecedor en su proyección sobre todo lo humano, y el soñar de Paulos, cada vez más encerrado en sí mismo, empobrecedor por lo que supone de aislamiento y de búsqueda del mero placer individual.

"CUADERNOS DE ESTUDIOS GALLEGOS", Tomo XL, Fascículo 105, Santiago 1992. 
-La conocía soñando. ${ }^{32}$

El calificativo de trascendente es aplicable en este caso porque aquello que se conoce es algo que va más allá de la mera experiencia sensitiva.

La progresiva profundización en el significado último del sueño parece alcanzar su cota máxima en las reflexiones de Paulos sobre el tema, quien llega a ser consciente de que no sólo vive su vida real, sino también la que sueña, y añadiendo un adjetivo a cualquier elemento, logra trastocarlo y convertirlo en fantástico ${ }^{33}$. En esta técnica de Paulos podemos entrever una revelación por parte del escritor de cómo lleva a cabo su tarea creadora, como ya ha observado la crítica en varias ocasiones.

Tan sólo nos queda destacar otra acepción novedosa del concepto de sueño en una última novela: la inclusión de una pareja de clara influencia unamuniana. La referencia al poder creador de la ensoñación no supone ninguna novedad. Pero sí lo es la óptica adoptada por influjo del pensamiento del autor vasco. Nos referimos a una secuencia en que un personaje secundario reconoce ser fruto de la imaginación de Paulos, y así se lo comunica a él ${ }^{34}$. El diálogo entre creador (Paulos) y criatura (Mr. Grig) recuerda el de Augusto, personaje de Niebla, con el propio Unamuno.

Y así hemos finalizado nuestra indagación del concepto básico de la estructura narrativa cunqueiriana. Para sistematizar todas las connotaciones que hemos hallado en las cuatro novelas utilizaremos, a modo de síntesis, el siguiente esquema. Los títulos entre paréntesis significan que tal connotación o enfoque figura sólo en la obra mencionada:

${ }^{32}$ CUNQUEIRO, A.: ob. cit., pp. 66.

${ }^{33}$ CUNQUEIRO, A.: ob. cit., pp. 81.

${ }^{34}$ iAh, el poder de la imaginación, amigo Paulos, que bien conozco el de la tuya, pues que me estás imaginando!

(CUNQUEIRO, A.: ob. cit., pp. 227).

"CUADERNOS DE ESTUDIOS GALLEGOS", Tomo XL, Fascículo 105, Santiago 1992. 


\begin{tabular}{|c|c|c|}
\hline & 1 - CREADOR & $\begin{array}{ll}\text { BIENHECHOR } & \begin{array}{l}\text { Para el propio individuo } \\
\text { Parala comunidad (altruísmo) } \\
\text { (El año del cometa) }\end{array} \\
\text { MALEFICO } & \end{array}$ \\
\hline & \multicolumn{2}{|c|}{$\begin{array}{l}2 \text { - PATRIMONIOPRIVILEGIADO } \\
\text { DEFABULACIONES (Las mocedades...) }\end{array}$} \\
\hline & \multicolumn{2}{|c|}{$\begin{array}{l}3 \text { - REVULSIVO DEL MIEDO } \\
\text { Y GENERADOR DE CONFIANZA } \\
\text { (Las mocedades...) }\end{array}$} \\
\hline & \multicolumn{2}{|c|}{$\begin{array}{l}4 \text { - FUENTE DE ETERNA JUVENTUD } \\
\text { (Un hombre...) }\end{array}$} \\
\hline & 5 - CARENCIA & $\begin{array}{l}\text { - MELANCOLIA } \\
\text { - DEGRADACION } \\
\text { - MUERTE }\end{array}$ \\
\hline \multirow{6}{*}{$\begin{array}{l}\text { ELEMENTO } \\
\text { OPERATIVO } \\
\text { BASICO: } \\
\text { SUEÑO }\end{array}$} & \multicolumn{2}{|c|}{$\begin{array}{l}6 \text { - MANIFESTACION DE FRUSTACIONES } \\
\text { OCULTAS } \\
\text { (Un hombre...) }\end{array}$} \\
\hline & \multicolumn{2}{|c|}{$\begin{array}{l}7 \text { - SU ENTREGA - MAXIMA PRUEBA DE AMOR } \\
\text { (Un hombre...) }\end{array}$} \\
\hline & \multicolumn{2}{|c|}{ AMADA - ESTIMULO PARA LA ENSOÑACION } \\
\hline & 8 - SINONIMO & DE MEMORIA (Un hombre...) \\
\hline & \multicolumn{2}{|c|}{9 - POTENCIADOR DE LOS IDELAES } \\
\hline & \multicolumn{2}{|c|}{$\begin{array}{l}10 \text {-VIA DE CONOCIMIENTO TRASCENDENTE } \\
\text { (El año del cometa) }\end{array}$} \\
\hline
\end{tabular}

"CUADERNOS DE ESTUDIOS GALLEGOS", Tomo XL, Fascículo 105, Santiago 1992. 
Como vemos, del amplio abanico de interpretaciones únicamente la sexta y una parte de la primera presentan un carácter negativo con respecto al sueño. Por lo tanto, parece evidente su carácter mayoritariamente positivo. Observemos también que los enfoques que más se repiten en las novelas estudiadas son el primero, el quinto y el sexto.

Ello significa que Cunqueiro valora el sueño sobre todo por su capacidad de dar origen a una nueva realidad, hasta el punto de que: El sueño, en su ficción, es la única verdad, lo que la constituye. (...) Parece tener más realidad que la realidad misma, en cuanto que el hombre está constituído por sus sueños, y es la fantasía la que nos da la medida del espíritu del hombre. ${ }^{35}$

Y respecto a su vinculación con los ideales nos dice Pilar Palomo: "Sueño" aparece incesantemente en su utilización metafórica de "deseos" $o$ "ideales" que, una vez que las circunstancias han imposibilitado su cumplimiento, se cubren de nostalgia. Pero un sueño vivido puede llegar a ser sinónimo de vida, de sí mismo, de la propia personalidad. ${ }^{36}$

Desde estas concepciones no resulta, pues, extraño que el cese de la actividad soñadora conduzca a la destrucción y a la muerte, real o metafórica, del personaje... y del hombre.

${ }^{35}$ MARTINEZ TORRON, D.: ob. cit., pp. 51.

${ }^{36}$ PALOMO, P.: Alvaro Cunqueiro: Vida y fugas de Fanto Fantini. En El comentario de textos CASTALIA, Madrid, 1977, pp. 227-245.

"CUADERNOS DE ESTUDIOS GALLEGOS", Tomo XL, Fascículo 105, Santiago 1992. 